\title{
Sustainability and Health
}

\author{
Dr. S. Srividya ${ }^{1 *}$, Dr. A. Velayudhan ${ }^{2}$
}

\section{ABSTRACT}

The term health has been long defined from the epidemiological perspective "as the state of being free from illness or injury". However, the concept of health has undergone a transition from absence of illness to better and healthy life for oneself and for future generations. This requires promotion and protection of not only our body system but also natural environment that surrounds us. The interlink between Health and Environment has begun to be recognized with the beginning of understanding on sustainability and sustainable development. Hence, there is a present need to look at health from epidemiological perspective to ecological perspective which would make the entire human kind sustainable. The present paper discusses the indiscernible cycle of sustainable environment- development- health from multiple levels- individual, family, and community as a whole. While sustainable healthy behavior at the individual level should be understood from the interactions of beliefs and behavior and action, families and communities should encourage health-promoting environments for sustainable communities and neighborhoods. The paper discusses various challenges of sustainable environments towards health at the various levels.

Keywords: Sustainability, Health and Environment.

The impact of several decades of industrialization which has resulted in environmental exploitation has begun to be felt as the whole existence of humankind itself is challenged due to climate change, rising global temperatures etc., The challenge would continue to daunt several generations as environmental sustainability is becoming more difficult. The following statistics are presented by Human Development Report (2011) on Sustainability and Equity would give a birds-eye view on how earth system has been endangered.

\footnotetext{
${ }^{1}$ UGC Post Doctoral Research Fellow, Department of Psychology, Bharathiar University

2 Professor, Department of Psychology, Bharathiar University

*Responding Author

(C) 2016 I S Srividya, A Velayudhan; licensee IJIP. This is an Open Access Research distributed under the terms of the Creative Commons Attribution License (http://creativecommons.org/licenses/by/2.0), which permits unrestricted use, distribution, and reproduction in any Medium, provided the original work is properly cited.
} 
Table 1: Human Development Report (2011) on Sustainability and Equity

\begin{tabular}{|l|c|c|}
\hline \multicolumn{1}{|c|}{ Earth-system process } & Current value & Boundary value \\
\hline $\begin{array}{l}\text { Climate change Atmospheric carbon dioxide } \\
\text { concentration (ppm by volume) }\end{array}$ & 387 & 350 \\
\hline $\begin{array}{l}\text { Biodiversity loss-Extinction rate (number of } \\
\text { species per million per year) }\end{array}$ & 121 & 35 \\
\hline $\begin{array}{l}\text { Biochemical- Anthropogenic nitrogen removed from } \\
\text { the atmosphere } \\
\text { (millions of tonnes per year) }\end{array}$ & 11.7 & 15 \\
\hline \begin{tabular}{l} 
Land use-Land surface converted to cropland (percent) \\
\hline $\begin{array}{l}\text { Fresh water- Global human consumption of water } \\
\text { (km/yr) }\end{array}$
\end{tabular} & 2600 & 4000 \\
\hline $\begin{array}{l}\text { Ozone layer- Stratospheric ozone concentration } \\
\text { (Dobson units) }\end{array}$ & 283 & 276 \\
\hline
\end{tabular}

Source: UNDP (2011)

The role of human behavior in creating unsustainable actions is undeniable and the solution to the challenge remains in changing the ways of human production, consumption and perceptions towards future needs. And this is possible only by means of sustainability. The term "Sustainability" is defined as an ability or capacity of something to be maintained or to sustain itself, without jeopardizing the potential for people in the future to meet their needs. It must be understood that any challenge to sustainability threatens not only environmental systems but also human systems and especially human health. According to Bonnes and Bonaiuto (2002) sustainable behavior refers to the set of deliberate and effective actions that result in the conservation of the socio-physical environment for present and future generations. Thus sustainable behavior should include actions resulting in the conservation of the physical environment, and also behaviors aimed at protecting other individuals and groups, especially the most vulnerable. Thus sustainable behaviours offer scope for equitable access to the use of natural resources (Ehrlich \& Ehrlich, 2004), moderate consumption, develops positive psychological behaviors such as altruism (Schultz, 2001) frugal/ austere behaviours (Winter, 2002).

\section{Link between Sustainability and Health}

The term health has been long defined from the epidemiological perspective "as the state of being free from illness or injury”. However, the concept of health has undergone a transition from absence of illness to better and healthy life for oneself and for future generations. Thus the definition has begun to include how humans can remain healthy across generations. This has made a transition in the understanding of the term health from epidemiological perspective. In order to have healthy generations, there is a need to understand the link between ecology and health. A healthy environment would enhance the well being of the individual both physically 


\section{Sustainability and Health}

and psychologically. Recent statistics by WHO show that Non-communicable diseases or lifestyle disease were responsible for $68 \%$ of all deaths globally in 2012 . The reasons stated for these lifestyle deaths are faulty choices in terms of food, lack of physical activity, pollution, stressful life style and erratic changes in climatic conditions due to El Nino resulting in crop failure and poor production These faulty choices are made due to undermining the link between ecology and health.

Figure 1: Link between Sustainability and Well being

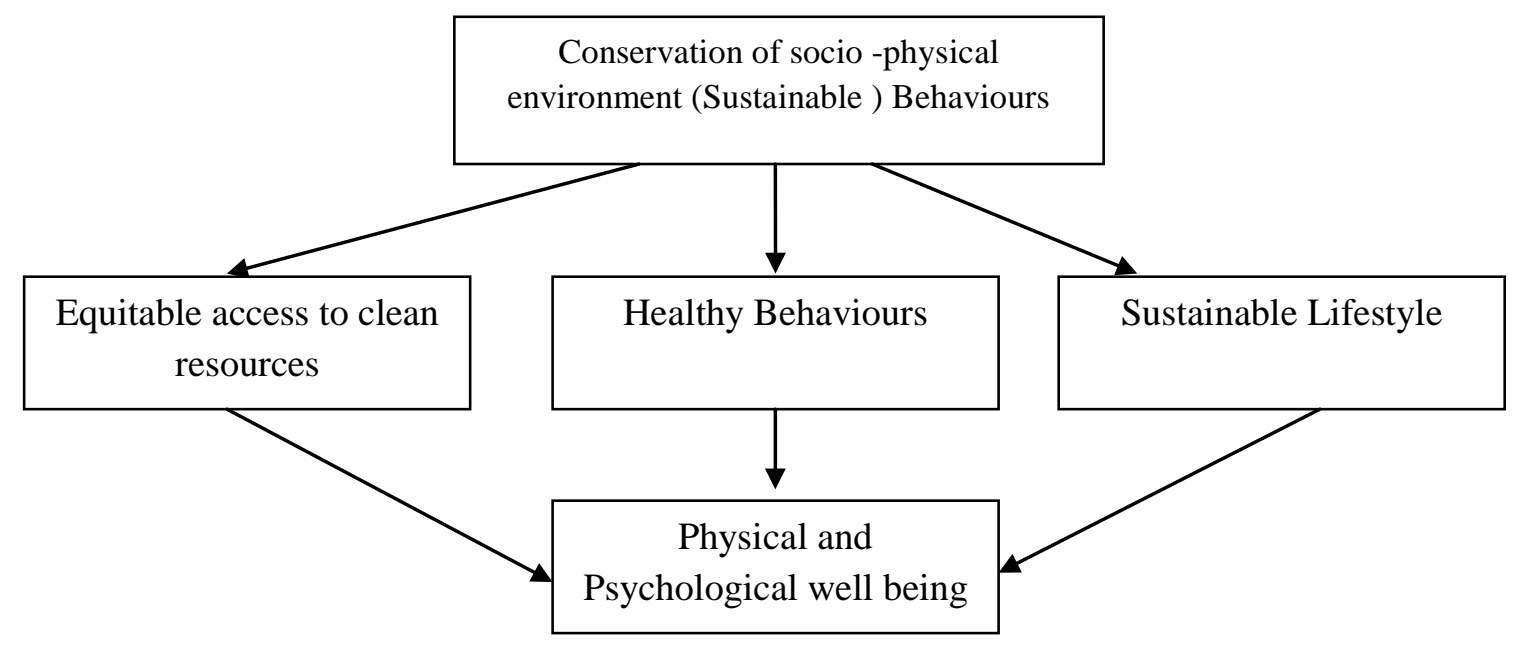

Hence, in order to have a healthy and sustainable lifestyle, tremendous human effort and changes across globe need to be made at all levels - individual, local, regional, and global scales in various spheres of human life from food, water usage, transportation modes, travel and leisure activities, usage of environmental systems. The underlying complementary relationship between sustainability and health also needs to be understood. Sustainable healthy behaviors begin at the individual level. Hence there is a need for paradigm shift in the understanding the term healthy sustainable behaviors.

\section{Health Psychology and Sustainability}

Health psychology offers scope to examine how strategies that are framed with ecological underpinning towards human health can make life sustainable. This requires a paradigm shift on how health is viewed. Health psychology needs to look health from epidemiological perspective to ecological perspective. This would offer scope in changing the perception of behavioral change that can stimulate and support personal choices for good health and environment alter attitudes enhance altruistic tendencies, create positive emotional dispositions, and develop prosocial behavior. This would also help people to acquire the skills needed for change in their personal lives and towards environment. The following paragraphs have tried to examine how Health and Sustainability are intermingled in various aspects of human day to day life and the scope of health psychology in these areas of sustainability and health. 


\section{Sustainability and Health}

\section{Food, Health and Sustainability}

It is has been widely acknowledged that present food consumption pattern is a threat to environment and environmental systems. Especially, excessive consumption patterns has led to exploitation of water resources for irrigation aggravating water scarcity, use of pesticides for excessive production which would make the land barren after few yields, industrial-scale livestock production leading to use of antibiotics for livestock. The unhealthy consumption patterns have not only devastated environmental systems but have also lead to unprecedented growth of non-communicable diseases such as diabetes, Coronary Heart diseases, and various cancers. One of the dreaded example of how environmental systems can destabilize the human existence is the increasing number of antibiotic resistant organisms such, such as the New Delhi Metallo-beta-lactamase-1 (NDM-1) a Super bug which is found in drinking water samples in New Delhi. Thus the present food consumption patterns are unsustainable to human and environmental systems. Health psychology offers the scope to challenge this link in food consumption patterns that stimulate and support personal choices for good health, reduced meat intake, encourage plant based food, organic production of food, zero pesticides, use of natural predators to control pests, generic traditional meals over large course meals etc.,

\section{Transport, land-use strategies, health and sustainability}

The effects on human health as a result of transport and land-use strategies are increasingly widely recognized. With rapid urbanization, sustainable development at the urban landscape is being challenged by rising pollution which has led to increased amount of lead and carbon monoxide in the environment especially in the Suspended Particular matter (SPM). The SPM which consists of particles in the air is a mixture of organic substances such as fumes, smoke, dust and aerosols due to the combustion process of motorized vehicles and transformation of gaseous emissions like oxides of sulphur and nitrogen. The major sources of the SPM in urban landscape are due to burning of coal, oil and gaseous fuels; municipal solid waste; fly-ash emissions from power plants; smelting and mining activities from polluting activities from suburban industries such as asbestos, metallurgical industries; ceramic, glass and cement industries. According to United Nations Environment Programme, Particulate Matter of less than 3 microns cause breathing problems and irritation of the lung capillaries, respiratory morbidity, deficiencies in pulmonary (lung) functions including decreased lung function (especially in children), and lung cancer with the consequence of increased mortality. Chronically reduced lung capacity (emphysema) among the urban population is also a major risk.

With increasing density of human population in per square kilometer, quality of life is decreasing. Health psychologists can offer solutions through interventions using pull and push strategies. "Pull" strategies are interventions that aim at increasing use of non conventional energy vehicles such as electric cars, bikes, public transport, car pooling, use of bicycles can be formulated at the individual level. Another strategy that can be encouraged is the "one way car" in which the commuter uses his personal car for one way trip to work and return using public transport and would take the public transport again the following day to return by his personal 


\section{Sustainability and Health}

car. This can minimize usage of cars for travelling to work. Some of the "push" strategies such availability of community space for outdoor health activities, "no vehicle” neighborhood areas, clean city campaigns, can be formulated at the society/community level. Health psychologist in collaboration with city planners could create local shopping spaces that would help an individual less dependent on cars.

\section{Lifestyles, Health and sustainability}

Most of the modern lifestyle practices are unsustainable because of overproduction and overconsumption. For example, household consumption such as excessive use of water, electricity dependence, cozy lifestyle comforts such as air-conditioners, home theatre, private gyms, swimming pools, excessive consumerism, etc. These lifestyles are becoming burden to natural resources, and economic burden. Health psychologists can offer sustainable strategies wherein a joint family meal time, use of renewable energy sources such as solar heaters, eco efficient appliances, localized open social spaces for life style changes in leisure and outdoor activities. Health psychologists could offer scope for encouraging healthy sustainable behaviors that prevent excessive consumerism, simplistic lifestyle changes, change in relaxation and perception of relaxation, community social work as healthy behaviors. These would encourage more social interaction and reduce several physical and psychological ailments.

However, there are several challenges in an intervention in health psychology that can offer. The challenges come from micro to macro level and health has to be looked from the context of sustainable development. This requires behaviour change to occur at the level of persons (individuals), of people (communities) and of populations (nations) so that the health of the planet is also protected.

\section{Challenges in interventions on health psychology and sustainability}

Individual Level: At the level of the individual, sustainable behaviours there is interplay between beliefs, behaviours and action that affects the balance between health and disease. It is usually considered that a health is a result of individual personal choices. However, in several cases, health is not solely dependent on the individual, but is due to interplay of situational, behavioural and environmental change. Hence, at individual level, the primary goal of health psychology should be to educate the individual as to what are healthy sustainable behaviours and how they can be maintained across the lifespan. Several research works have pointed out that behaviour change is best accomplished when education is accompanied by policies that enable individuals (Rockström et al. 2011)

Hence interventions at the individual level should focus on strategies to assist, motivate and inspire behavioural change, as well as the role of infrastructure and enabling sustainable living environments in day to day life. Some of the suggestions are

$>$ Use the power of incentives or tangible rewards (such as "join the joggers club (healthy sustainable behavior) and get a film show ticket”) is crucial in bringing about large and 


\section{Sustainability and Health}

sustainable behavior change. This would help in initially stimulating the sustainable behavior.

$>$ Interventions should be based on understanding of the situational behavior (placards such as "Use stairs and have a healthy heart" being put out in malls), incite its relevance, raise awareness and encourage acceptance, should be made convenient and stimulate confidence, improve the individual's self image, the results of the intervention are rewarding (use of water solar water heaters reduces your electricity bills), repetition to the set of behaviours such that it becomes a habit (use a bicycle instead of a car for grocery shopping) in everyday setting. This would stimulate and support personal choices for good health

$>$ Examining the underlying role of motives to target sustainable health behaviors-Theories in Health psychology such as Theory of Planned Behaviour [Fishbein, and Ajzen,1975), the Health Belief Model (Janz, and Becker, 1984) assumes that behaviour is cognitive, conscious and calculated to produce rational outcomes. However, most behaviour are driven by psychological motives such as need for affiliation, need for acceptance from peer group, community etc., Hence interventions should be targeted on motives that encourage sustainable behavior.

> Another important aspect that can be targeted is the Habit. Sustainable habits needs to be conditioned in daily routine. This can be achieved by targeted interventions with underlying emotions such as status (celebrities to endorse a sustainable health behaviours), attraction (“you leave no carbon print when you use this product”), disgust (create bad image for unsustainable act), nurture ("Mother earth thanks you for this kind act”) and affiliation (Car pooling helped know my neighbours).

However one of the main challenges that health psychologist face is that behaviour change is ineffective if it is compromises the current behavior. Hence intervention should be administered not as a change in the routine but as a part of routine. Instead the changes should be (a) able to unlearn old behaviors, (b) satisfy the individual's needs (c) require periodical positive reinforcement or feedback, (d) the present behavior is more pleasurable than the previous one and (d) one change is brought at a time. For example, instead of reducing meat consumption, a snack made of fruits if introduced as refreshment would bring down the appetite and if habituated over a period of time would reduce intake of processed meat.

Families and community: At the level of families and communities, cultural perceptions, social and economic priorities and pathways of access to health-promoting environments as well as health services which are key determinants of health. For example, leisure activities that focus more on sports and physical activities if encouraged in family could also reduce couch-time and improve family health. Similarly, family meal time reduces excessive food consumption, encourage smaller meals, reduced unhealthy meals, and healthy eating. This should be modeled making behaviour the norm, demonstrating the benefits, reinforcing and reminding that family togetherness can make sustainable lifestyle choices. 


\section{Sustainability and Health}

Industry and Market: One of the key players in the role of sustainability and health is the market and its standards which set standards for production and consumption. Hence it is imperative that innovation and technology that push products into the market need to support designs that encourage behavioural change that are sustainable. However, changing population behaviour in regards to diet and nutrition, lifestyle, hygiene and sustainability is difficult and complex. This requires sharing expertise with academics, research and formulating interventions through private-public partnerships on sustainability and health. The market and industry has the social responsibility of production which is not only sustainable and healthy but also encourages mass market adoption. Only then the product would reach the depth of the society. A product which is unsustainable would bring about inequality, and would encourage unhealthy products in the market such as dumping of various unsustainable Chinese products right from consumer goods to food products in other markets, especially in India.

National and global levels: Since health transition is increasingly being influenced by social environment, behaviour change is also needed at the societal level. Policy interventions that interlink ecology and human health needs to be formulated right from (a)urban development that offers scope for healthy lifestyles such as walking spaces, cyclists pathways, (b) encouraging organic food products, plant based foods (c) urban constructions with more play space should be encouraged.

Figure 2: Role of various stakeholders in sustainable health behaviors

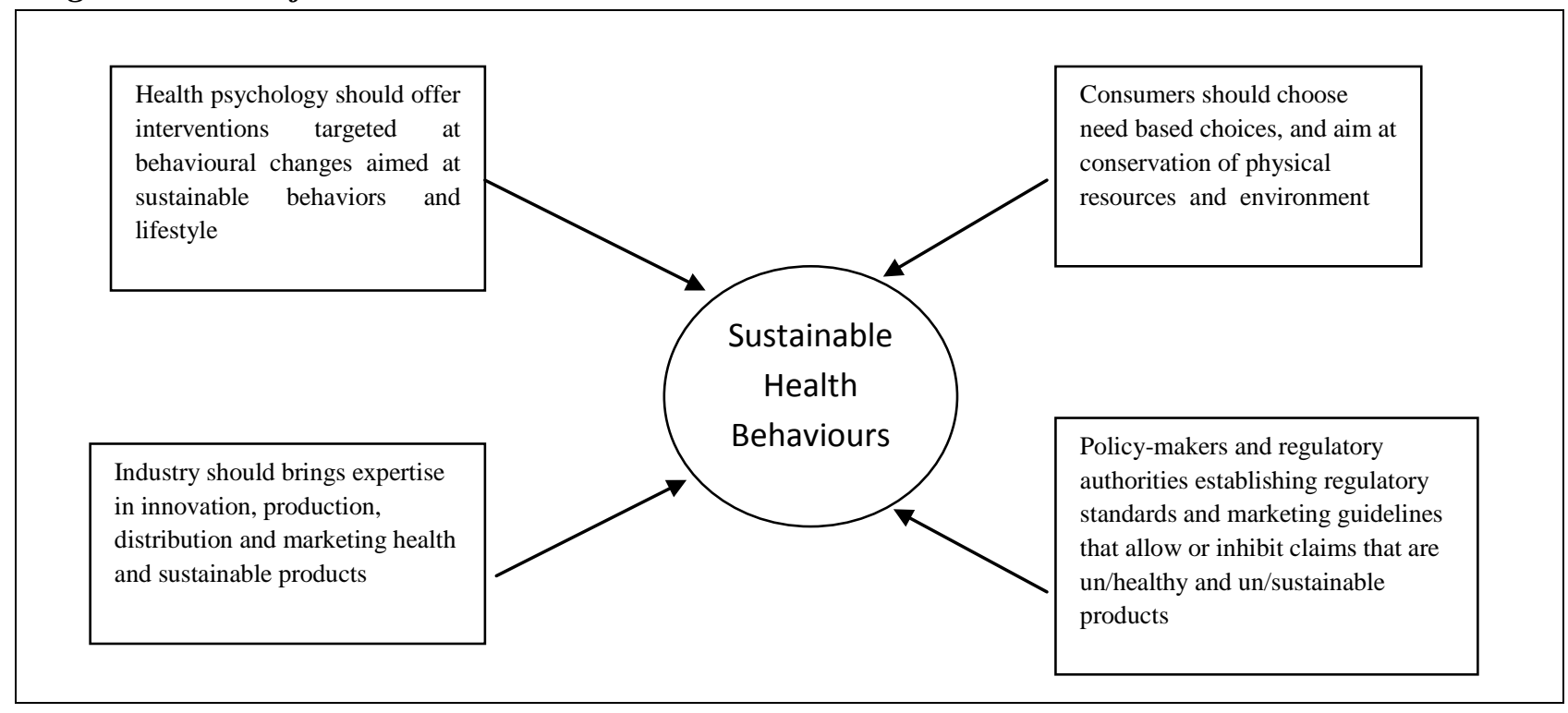

\section{CONCLUSIONS}

A change in behavior that promotes health and sustainability is quite challenging. Sustainability offers clean air, water, oneness with nature and a life with few needs as a result of sustainable lifestyles. It also marks a state of health free from illness, a change in the perception of purpose of life, satisfaction, and personal wellbeing. Above all, according to Talbert(2008), and Gardner 


\section{Sustainability and Health}

and Prugh (2008)one of the positive consequence of sustainability is happiness or subjective wellbeing and practices of sustainable behaviors makes a happy society. According to Marks (2006), the Happy Planet Index (HPI), assesses the ecological efficiency with which people achieve long and happy lives. The HPI is computed by multiplying an index of life satisfaction and the life expectancy average, then dividing the obtained product by the ecological footprint. The research evidence of Marks Marks, Simms, Thompson, and Abdallah (2006) presents evidence showing that the HPI (and, therefore, a happy life) is higher in countries that are more sustainable in terms of their consumption of natural resources.

\section{REFERENCES}

Bonnes, M., \& Bonaiuto, M. (2002). Environmental psychology: from spatial-physical environment to sustainable development. In R.B. Bechtel \& A. Churchman (Eds.), Handbook of Environmental Psychology (pp. 28-54). New York: Wiley.

Ehrlich, P. \& Ehrlich, A. (2004). One with Niniveh. Politics, Consumption and the Human Future. Washington, DC: Shearwater Books.

Fishbein, M. \& Ajzen, I. (1975). Belief, attitude, intention, and behavior: An introduction to theory and research. Reading, MA: Addison-Wesley.

Gardner, G. \& Prugh, T. (2008). Seeding the sustainable economy. In Starke, L. (Ed.), State of the World. New York, W. W. Norton \& Company

Janz, N, K. \& Becker, M., H. (1984). "The Health Belief Model: A Decade Later". Health Education Behavior 11 (1): 1-47. doi:10.1177/109019818401100101. Retrieved 1/2/16

Marks, N., Simms, A., Thompson, S. \& Abdallah, S. (2006). The Happy Planet Index: an index of human well-being and environmental impact. Londres: New Economics Foundation and Friends of Earth.

Rockström, J., Steffen, W., Noone, K., Persson, A., Chapin, F.S., Lambin, E.F., Lenton, T.M., Scheffer, M., Folke, C., Schellnhuber, H.J., et al. (2009). A safe operating space for humanity. Nature, 461, 472-475.

Schultz, P.W. (2001). The structure of environmental concern. Concern for self, other people, and the biosphere. Journal of Environmental Psychology, 21, 327-339.

Talbert, J. (2008). Redefining progress. En Starke, L. (Ed.), State of the World. New York, W. W. Norton \& Company

UN Human Development Report (2011). Sustainability and Equity: A Better Future for All

Winter, D. (2002). (En) Gendering sustainable development. En P. Schmuck \& P.W. Schultz (Eds.), Psychology of Sustainable Development. Norwell, Massachusetts: Kluwer.

How to cite this article: S Srividya, A Velayudhan (2016), Sustainability and Health, International Journal of Indian Psychology, Volume 3, Issue 3, No. 6, DIP: 18.01.103/20160303 